\title{
Disruption of Bovine Oocytes and Preimplantation Embryos by Urea and Acidic $\mathrm{pH}^{1}$
}

\author{
O. M. Ocon ${ }^{2}$ and P. J. Hansen \\ Department of Animal Sciences, University of Florida, \\ Gainesville, 32611-0910
}

\begin{abstract}
Feeding cattle diets high in degradable crude protein $(\mathrm{CP})$ or in excess of requirements can reduce fertility and lower uterine $\mathrm{pH}$. Objectives were to determine direct effects of urea and acidic $\mathrm{pH}$ during oocyte maturation and embryonic development. For experiment 1 , oocytes were matured in medium containing 0,5 , 7.5 , or $10 \mathrm{~m} M$ urea $(0,14,21$, or $28 \mathrm{mg} / \mathrm{dl}$ urea nitrogen, respectively). Cleavage rate was not reduced by any concentration of urea. However, the proportion of oocytes developing to the blastocyst stage at d 8 after insemination was reduced by $7.5 \mathrm{~m} M$ urea. In addition, the proportion of cleaved oocytes becoming blastocysts was decreased by 5 and $7.5 \mathrm{~m} M$ urea. For experiment 2 , putative zygotes were collected $\sim 9 \mathrm{~h}$ after insemination and cultured in modified Potassium Simplex Optimized Medium (KSOM). Urea did not reduce the proportion of oocytes developing to the blastocyst stage, although $10 \mathrm{~m} M$ urea reduced cleavage rate slightly. For experiment 3, dimethadione (DMD), a weak nonmetabolizable acid, was used to decrease culture medium $\mathrm{pH}$. Putative zygotes were cultured in modified KSOM containing $0,10,15$, or $20 \mathrm{mM}$ DMD for $8 \mathrm{~d}$. DMD reduced cleavage rate at 15 and $20 \mathrm{mM}$ and development to the blastocyst stage at all concentrations. Results support the idea that feeding diets rich in highly degradable $\mathrm{CP}$ compromises fertility through direct actions of urea on the oocyte and through diet-induced alterations in uterine $\mathrm{pH}$.
\end{abstract}

(Key words: urea, $\mathrm{pH}$, preimplantation embryo, bovine)

Abbreviation key: COC = cumulus-oocyte complexes, DMD = dimethadione, KSOM = Potassium Simplex Optimized Medium.

Received April 5, 2002.

Accepted August 6, 2002.

Corresponding author: P. J. Hansen; e-mail: Hansen@animal. ufl.edu.

${ }^{1}$ This is Journal Series Number R-08755 of the Florida Agricultural Experiment Station. Research was supported in part by USDACSREES grant \# 2001-52101-11318.

${ }^{2}$ Present address: Dept. of Dairy and Animal Science, The Pennsylvania State University, University Park, 16802-3503.

\section{INTRODUCTION}

Feeding dairy cows large amounts of degradable protein in excess of requirements can reduce pregnancy rates per insemination (Canfield et al., 1990; Elrod and Butler, 1993). Diets high in protein content elevate urea nitrogen concentrations in plasma and uterine secretions (Jordan et al., 1983; Canfield et al., 1990; Elrod and Butler, 1993; Roseler et al., 1993), and elevations in blood or milk urea nitrogen concentrations have also been associated with low fertility (Butler et al., 1996; Larson et al., 1996; Rajala-Schultz et al., 2001).

The mechanism by which feeding large amounts of protein affects fertility is not completely known. One possibility is that high concentrations of urea associated with excess feeding of CP could disrupt oocyte growth or maturation, fertilization, or development. Feeding a diet generating large amounts of urea and ammonia increased growth of the second-wave dominant follicle, decreased capacity of oocytes from small ( 1 to $4 \mathrm{~mm}$ ) and medium ( $>4$ to $8 \mathrm{~mm}$ ) follicles to cleave when fertilized in culture, and decreased ability of cleaved embryos formed from oocytes obtained from medium-sized follicles to develop in culture to the blastocyst stage (Sinclair et al., 2000). Moreover, exposure of oocytes to $6 \mathrm{mM}$ of urea during maturation in vitro impaired meiosis and fertilization rate (De Wit et al., 2001).

Feeding large amounts of protein can also alter the uterine environment by reducing concentrations of magnesium, potassium, and phosphorus in uterine secretions (Jordan et al., 1983) and by reducing uterine pH (Elrod et al., 1993; Elrod and Butler, 1993). Effects of protein diet on potassium, phosphorus, and $\mathrm{pH}$ were only observed during the luteal phase. Although consequences of altered mineral concentrations on embryonic function are not known, a reduction in $\mathrm{pH}$ from 7.2 to between 6.9 and 7.1 has been reported to compromise embryonic development in mice (Edwards et al., 1998). In contrast, development of hamster preimplantation embryos was unaffected by a range of $\mathrm{pH}$ from 6.5 to 7.4 (Bavister et al., 1983; Carney and Bavister, 1987). 
Objectives of the present study were to 1) determine direct effects of urea on oocyte maturation and embryonic development and 2) evaluate whether low $\mathrm{pH}$ during the period of embryonic growth disrupts development. To test effect of $\mathrm{pH}$, embryos were cultured in varying concentrations of dimethadione (DMD), a nonmetabolizable weak acid that lowers $\mathrm{pH}$ of the culture medium and has been used to study effects of $\mathrm{pH}$ on development of hamster and mouse embryos (Carney and Bavister, 1987; Edwards et al., 1998).

\section{MATERIALS AND METHODS}

\section{Materials}

Materials for in vitro maturation, fertilization, and embryo culture were obtained as described previously (Rivera and Hansen, 2001). Urea was purchased from Research Organics (Cleveland, OH), and hyaluronidase and dimethadione (5,5-dimethyl-2, 4-oxazol-idinedione) were from Sigma (St. Louis, MO). Frozen semen from bulls of several breeds (Angus, Holstein, and Brangus) was donated by Select Sires Inc. (Rocky Mount, VA) or was purchased from Southeastern Services Inc. (Wellborn, FL) or American Breeders Service (Madison, WI).

\section{In Vitro Production of Embryos}

In vitro production of embryos was performed as described by Rivera and Hansen (2001) using oocytes recovered from ovaries obtained at a local abattoir. Briefly, oocytes were collected by slashing the ovaries and washing in oocyte collection medium (Tissue Culture Medium 199 with Hank's Salts without phenol red, supplemented with $2 \%$ [vol/vol] bovine steer serum [containing $2 \mathrm{U} / \mathrm{ml}$ heparin], $1 \mathrm{~m} M$ glutamine, $100 \mathrm{U} / \mathrm{ml}$ penicillin-G, and $0.1 \mathrm{mg} / \mathrm{ml}$ streptomycin). Groups of 10 cumulus-oocyte complexes (COC) were matured by culture in 50- $\mu$ l microdrops of oocyte maturation medium (Tissue Culture Medium 199 with Earle's Salts supplemented with 10\% [vol/vol] bovine steer serum, $50 \mu \mathrm{g} / \mathrm{ml}$ gentamicin, $20 \mu \mathrm{g} / \mathrm{ml} \mathrm{FSH,} 2$ $\mu \mathrm{g} / \mathrm{ml}$ estradiol- $17 \beta, 22 \mu \mathrm{g} / \mathrm{ml}$ sodium pyruvate, and 1 $\mathrm{m} M$ glutamine) for 21 to $24 \mathrm{~h}$ at $38.5^{\circ} \mathrm{C}$ and $5 \%$ (vol/ vol) $\mathrm{CO}_{2}$ in humidified air. Following maturation, $\mathrm{COC}$ were washed and groups of 30 oocytes were placed in four well plates of $600 \mu \mathrm{l}$ of IVF-TALP (Parrish et al., 1986) supplemented with $25 \mu \mathrm{l}$ of a mixture of 0.5 $\mathrm{m} M$ penicillamine, $0.25 \mathrm{~m} M$ hypotaurine, and $25 \mu M$ epinephrine in $0.9 \%$ (wt/vol) $\mathrm{NaCl}$. The COC were fertilized with $\sim 1 \times 10^{6}$ Percoll-purified sperm/well (Parrish et al., 1986). For each replicate, sperm were prepared from a pool of semen from three bulls. A different pool of bulls was sometimes but not always used for each replicate. Following incubation for 8 to $10 \mathrm{~h}$ at $38.5^{\circ} \mathrm{C}$ and $5 \%(\mathrm{vol} / \mathrm{vol}) \mathrm{CO}_{2}$, putative zygotes were denuded of cumulus cells by vortexing and, if necessary, by incubation in $300 \mu \mathrm{g} / \mathrm{ml}$ of hyaluronidase in Hepes-TALP. Embryos were then cultured in Potassium Simplex Optimized Medium (KSOM), modified by adding $3 \mathrm{mg} / \mathrm{ml}$ bovine serum albumin (essentially fatty-acid free), $50 \mu \mathrm{g} / \mathrm{ml}$ gentamicin, Basal Medium Eagle essential AA solution, and Minimum Essential Medium nonessential AA solution. For embryo culture, putative zygotes were placed in drops of modified $\mathrm{KSOM}$ at $38.5^{\circ} \mathrm{C}$ and $5 \% \mathrm{CO}_{2}$ (vol/vol) in humidified air until d 8 after insemination. Cultures were performed in 25 - $\mu$ l drops, and each contained 10 to 20 embryos per drop. Within a replicate, numbers of embryos per drop were constant for all treatments. For each replicate, one or more drops (typically two) of embryos were prepared for each treatment.

\section{Experiments}

Effect of urea during oocyte maturation on cleavage and subsequent development. Groups of $\sim 10$ COC were transferred to drops of oocyte maturation medium containing $0,5,7.5$, or $10 \mathrm{~m} M$ urea. These concentrations are equivalent to $0,14,21$, and $28 \mathrm{mg} /$ dl urea nitrogen, respectively. Oocytes were matured for 21 to $24 \mathrm{~h}$, washed in Hepes-TALP medium, and then subjected to fertilization in wells without the presence of urea. After fertilization, putative embryos were cultured in 25- $\mu$ l drops of modified KSOM. Cleavage rate was recorded on $\mathrm{d} 3$ and the percentage of oocytes reaching the blastocyst stage recorded at $\mathrm{d} 8$. The experiment was replicated seven times with a total of 204 to 229 oocytes per treatment group.

Effect of urea on early embryonic development. Putative zygotes were produced by in vitro maturation and fertilization. After fertilization, groups of 10 to 20 putative zygotes were transferred to $25-\mu$ l drops of modified KSOM containing $0,5,7.5$, or $10 \mathrm{~m} M$ urea for the duration of culture. Embryos were examined on $\mathrm{d} 3,5,7$, and 8 for development. The experiment was replicated five times with a total of 167 to 180 putative zygotes per treatment group.

Effect of DMD on early embryonic development. A preliminary experiment was performed one time in which $\mathrm{pH}$ was measured in medium containing 0,10 , 15 , or $20 \mathrm{~m} M \mathrm{DMD}$ at various time points after incubation at $38.5^{\circ} \mathrm{C}$ and $5 \% \mathrm{CO}_{2}$ (vol/vol) in humidified air.

After fertilization, groups of 10 to 20 putative zygotes produced by in vitro maturation and fertilization were transferred to 25- $\mu \mathrm{l}$ drops of modified KSOM containing 0, 10, 15, or $20 \mathrm{mM}$ DMD. Embryos remained in these drops for the duration of culture. 
Cleavage rate was recorded on $\mathrm{d} 3$, and the percentage of oocytes reaching the blastocyst stage recorded at $d$ 8. The experiment was replicated three times with a total of 102 to 124 putative zygotes per treatment group.

\section{Statistical Analysis}

The proportion of oocytes that cleaved and the proportion of oocytes and cleaved embryos that became blastocysts was calculated for each replicate (i.e., for embryos from all drops treated alike in a given replicate). Data were analyzed by least squares ANOVA using the general linear models procedure of the Statistical Analysis System (SAS, 1989). The mathematical model included effects of treatment and replicate; the error term represents treatment $\times$ replicate. When the main effect of treatment was significant, means separation procedures were carried out using leastsquares means and the pdiff procedure of SAS to determine concentrations of urea that differed from untreated controls. Data were analyzed two ways-as untransformed data and after performing arcsin transformation. Probability values were similar for both analyses. Reported probability values are derived from the analysis of transformed data, whereas reported least-squares means and standard errors are derived from analysis of untransformed data.

\section{RESULTS}

\section{Effect of Urea During Maturation}

Cleavage rates were not reduced by urea at any concentration tested (Figure 1A). As compared with control oocytes, the proportion of oocytes that became blastocysts at $\mathrm{d} 8$ after insemination was reduced ( $P$ $<0.001$ ) by maturation in $7.5 \mathrm{~m} M$ urea but not by maturation in 5 or $10 \mathrm{mM}$ urea (Figure 1B). The proportion of cleaved embryos developing to blastocysts was decreased by $5(P<0.05)$ and $7.5 \mathrm{mM}$ urea $(P<$ 0.001 ) but not by $10 \mathrm{~m} M$ urea (Figure 1C).

\section{Effect of Urea During Embryonic Development}

The highest urea concentration tested $(10 \mathrm{mM})$ reduced $(P<0.05)$ cleavage rate slightly (Figure $2 \mathrm{~A}$ ). Nonetheless, in contrast to effects during maturation, urea did not reduce the proportion of oocytes (Figure $2 \mathrm{~B}$ ) or cleaved embryos (Figure 2C) developing to the blastocyst stage.

\section{Effect of DMD During Embryonic Development}

A preliminary study was conducted to describe the changes in the $\mathrm{pH}$ over time in media containing vari-

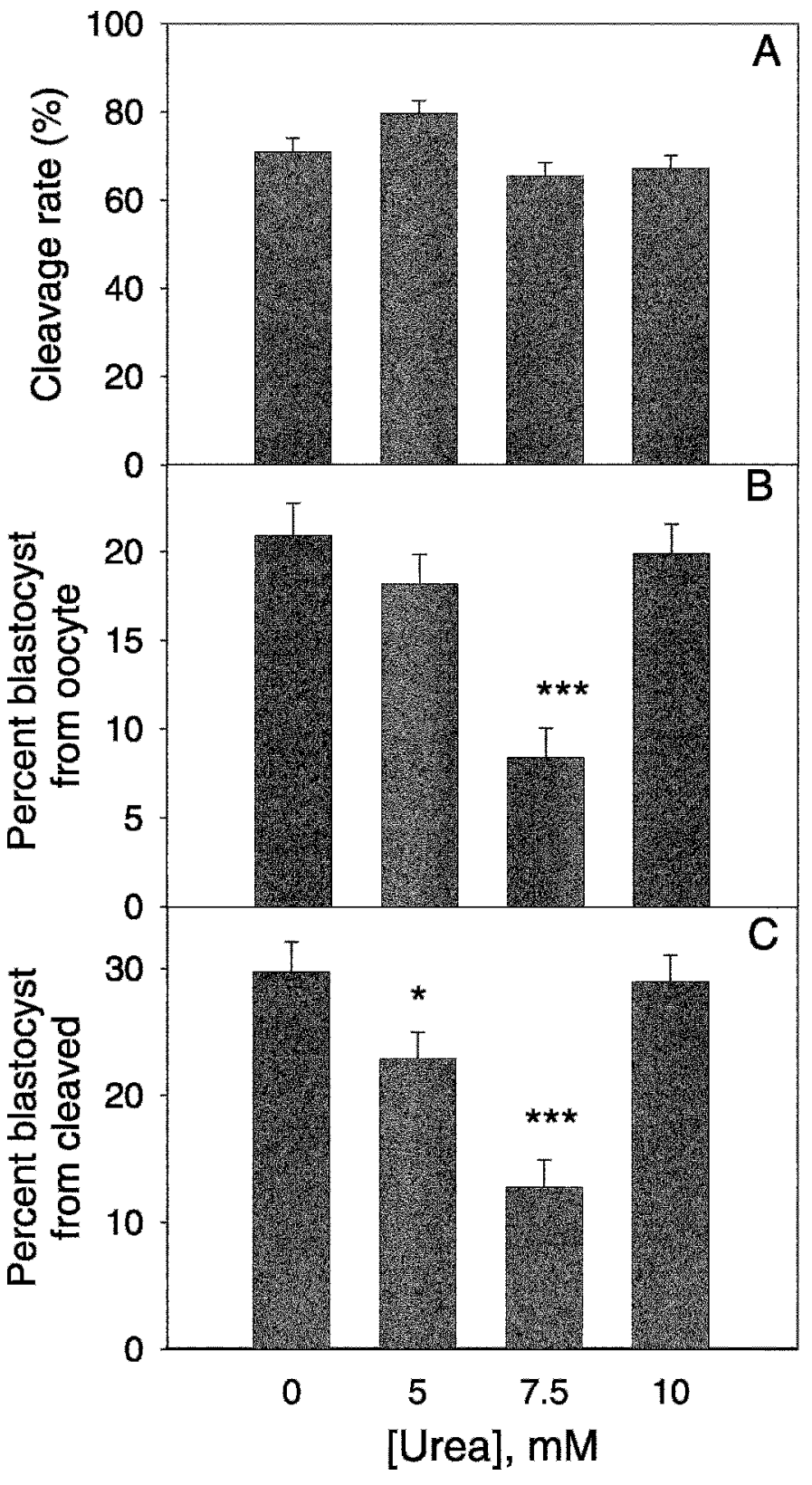

Figure 1. Development of bovine embryos treated with various concentrations of urea during in vitro maturation. The experiment was replicated seven times with a total of 204 to 229 oocytes per treatment group. Results are least-squares means \pm SEM. Means significantly different from $0 \mathrm{~m} M$ urea are indicated by asterisks $\left({ }^{*} P\right.$ $<0.05 ; * * * P<0.001)$.

ous concentrations of DMD (Figure 3). The initial $\mathrm{pH}$ values for modified KSOM with $0,10,15$, and $20 \mathrm{mM}$ DMD were $7.2,6.6,6.4$, and 6.3, respectively. After $24 \mathrm{~h}$ in $5 \% \mathrm{CO}_{2}$, the respective $\mathrm{pH}$ values were 7.4 , 7.1, 7.0, and 6.8.

As compared with controls, cleavage rate was not affected by $10 \mathrm{~m} M$ DMD but was reduced by $15(P=$ 


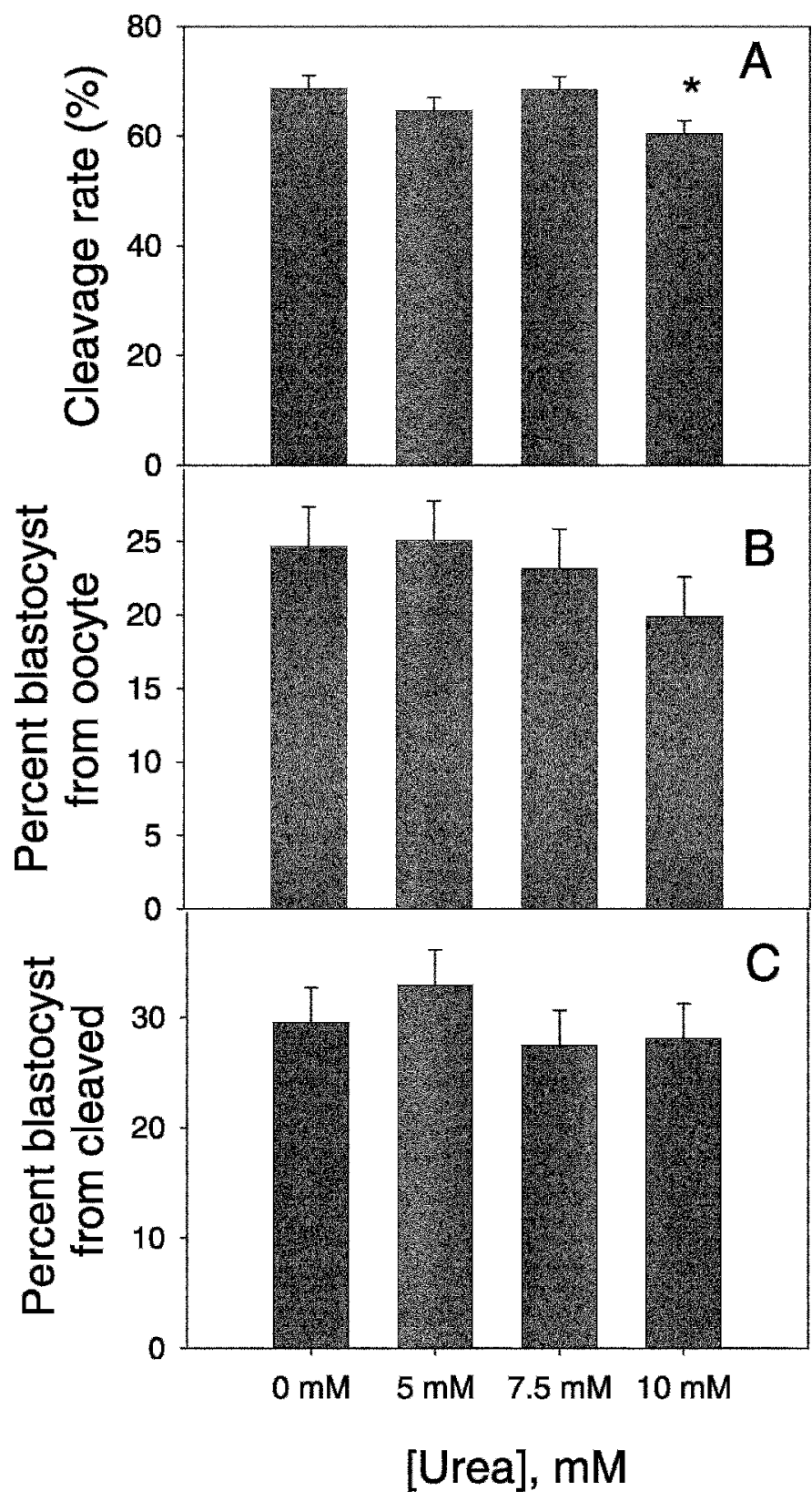

Figure 2. Development of bovine embryos treated with various concentrations of urea during culture. The experiment was replicated five times with a total of 167 to 180 putative zygotes per treatment group. Results are least-squares means \pm SEM. Means significantly different from $0 \mathrm{~m} M$ of urea are indicated by an asterisk $\left({ }^{*} P<0.05\right)$.

$0.05)$ and $20 \mathrm{mM}(P<0.01) \mathrm{DMD}$ (Figure 4A). Development to the blastocyst stage was significantly reduced by all concentrations of DMD regardless of whether data were expressed as percentage of oocytes developing to blastocysts (Figure 4B) or percentage of cleaved embryos developing to blastocysts (Figure 4C). The inhibition to development caused by DMD was nearly total; only $1.0 \%$ of oocytes cultured with $5 \mathrm{mM}$

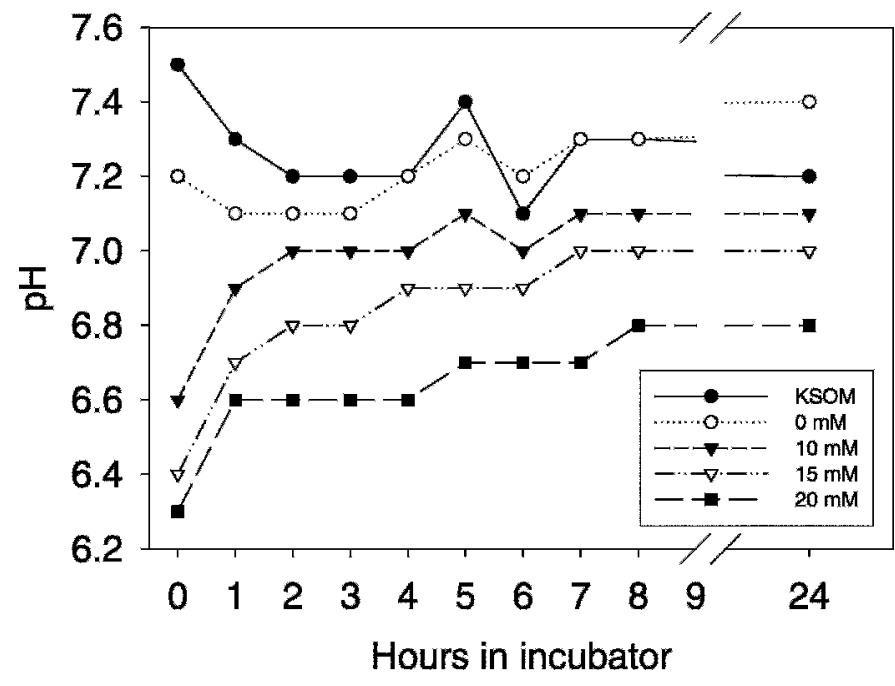

Figure 3. Effects of various concentrations of DMD on culture medium $\mathrm{pH}$ at $38.5^{\circ} \mathrm{C}$ and $5 \% \mathrm{CO}_{2}$. Values are plotted for modified KSOM, modified KSOM containing vehicle for DMD $(0 \mathrm{mM})$, and modified KSOM containing 10 to $20 \mathrm{mM}$ DMD.

DMD became blastocysts, and no oocytes cultured in 15 or $20 \mathrm{~m} M$ DMD reached the blastocyst stage.

\section{DISCUSSION}

In this study, exposure of oocytes to physiologically relevant concentrations of urea during the process of maturation interfered with ability of the embryos formed after fertilization to develop to the blastocyst stage. Exposure of the embryo to urea after fertilization had no effects on development, indicating that the embryo itself was resistant to direct effects of urea. However, development was impaired by embryonic exposure to acidic $\mathrm{pH}$ similar to those of uterine secretions from cows fed excess CP (Elrod et al., 1993; Elrod and Butler, 1993). Taken together, the results implicate changes in urea concentrations and uterine $\mathrm{pH}$ as a cause of infertility associated with feeding diets containing excess CP.

As in the present study, De Wit et al. (2001) also observed an effect of urea exposure during maturation on the proportion of oocytes becoming blastocysts. However, the cause for the decline in development to the blastocyst stage was different than was the case here. In particular, De Wit et al. (2001) observed that the addition of $6 \mathrm{~m} M$ urea to maturation medium hastened completion of metaphase I, inhibited completion of metaphase II, reduced fertilization rate, and decreased the proportion of oocytes that became blastocysts. There was no effect of urea exposure during maturation on development of cleaved embryos to the blastocyst stage. Thus, urea reduced the proportion of 


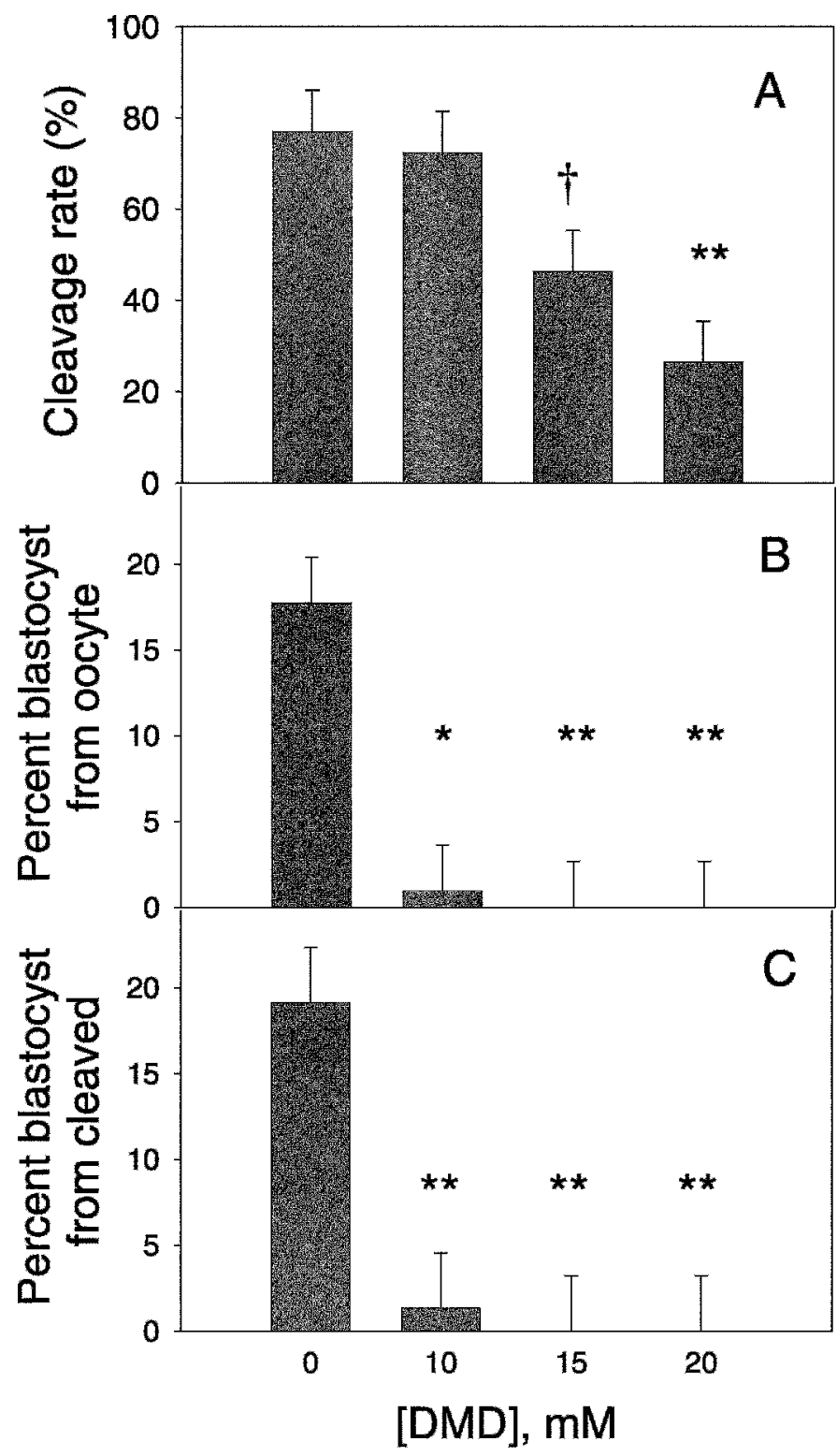

Figure 4. Effect of DMD during embryonic development. The experiment was replicated three times with a total of 102 to 124 putative zygotes per treatment group. Results are least-squares means \pm SEM. Means significantly different from $0 \mathrm{~m} M$ DMD are indicated by symbols $(\dagger P=0.05 ; * P<0.05$; $* * P<0.01)$.

oocytes becoming blastocysts because it reduced fertilization and cleavage rate, not because the embryos that were formed after fertilization were compromised. In the present study, in contrast, addition of urea during oocyte maturation did not inhibit cleavage rate but, rather, reduced the ability of cleaved embryos to become blastocysts. Thus, the overall reduction in the proportion of oocytes becoming blastocysts is attributed to decreased developmental competence of embryos formed from oocytes exposed to urea.
Differences in concentrations of urea between the two studies cannot account for the discrepancy between the current results and those of De Wit et al. (2001) because the reduction in development of cleaved embryos was observed in the present study at 5 and $7.5 \mathrm{~m} M$ urea. Perhaps differences in embryo culture media between the two studies are responsible for the discrepancy in effects of urea on embryo competence. The culture medium used in the study of De Wit et al. (2001) was complex and included serum, epidermal growth factor, insulin, and other constituents not present in the modified KSOM used in the present study. Future studies to determine whether specific nutrients or regulatory factors can overcome damage to the embryo caused by exposure of oocytes to urea or other stressors may lead to methods to improve embryonic survival under adverse conditions.

One surprising result of the current study was the observation that, in contrast to effects of 5 and 7.5 $\mathrm{m} M$ urea, exposure of oocytes to $10 \mathrm{~m} M$ urea during maturation did not affect cleavage or subsequent development. Conceivably, high concentrations of urea trigger some compensatory mechanism in the oocyte that increases resistance to urea toxicity. The nature of this phenomenon is unknown but is unlikely to involve transcription, because the oocyte is transcriptionally inactive during maturation and cannot respond to a cellular stress by increasing transcription of genes involved in cytoprotection. Heat shock, for example, can induce heat shock protein 70 synthesis at the two-cell stage but not in oocytes evaluated before or after completion of maturation (Edwards and Hansen, 1996). One possibility is that high concentrations $(>7.5 \mathrm{mM}$ ) of urea trigger changes in membrane transport of urea to either inhibit movement of urea inside the cell or remove urea from the cytoplasm. Carrier-mediated exchange of urea occurs in other cells (Verkman et al., 1985; Hisanaga et al., 1991; Kato and Sands, 1998), but the system of urea transport in the oocyte and its regulation by urea concentration is not known.

The impairment of events during oocyte maturation by urea occurred at concentrations that are probably physiologically relevant. This is so because the concentrations affecting maturation (5 and $7.5 \mathrm{mM}$; equivalent to plasma urea nitrogen concentrations of 14 and $21 \mathrm{mg} / \mathrm{dl}$ ) closely match the concentrations of urea in the plasma or milk of cows experiencing infertility due to excess feeding of CP (Canfield et al., 1990; Elrod and Butler, 1993; Butler et al., 1996; Larson et al., 1996; Rajala-Schultz et al., 2001). It is likely that feeding excess amounts of $\mathrm{CP}$ also elevates urea concentrations in the follicle, the site of oocyte maturation, al- 
though intrafollicular concentrations of urea have not, to our knowledge, been monitored.

Urea concentrations are elevated in uterine secretions of cows fed large amounts of CP (Jordan et al., 1983) and in oviductal-uterine flushings of ewes fed supplemental urea (McEvoy et al., 1997). However, in contrast to effects of urea on the oocyte, present results suggest that exposure to urea has little effect on embryonic development when embryos are exposed continuously from the one-cell stage. The only effect seen was a slight reduction in cleavage rate when $10 \mathrm{mM}$ urea was added after fertilization, suggesting that the highest concentration of urea tested inhibited ability of fertilized embryos to cleave. The reduction in cleavage rate was small, however, and addition of urea after fertilization did not reduce the proportion of embryos that developed to the blastocyst stage. Either the embryo may acquire some mechanism to counteract toxic effects of urea that the oocyte lacks, or urea is disrupting some process in the oocyte that does not occur during embryonic development.

In contrast to its resistance to urea, the embryo was very susceptible to disruption by reduction in $\mathrm{pH}$, suggesting that the reduction in uterine fluid $\mathrm{pH}$ in the luteal phase of cows fed a high-protein diet (Elrod et al., 1993; Elrod and Butler, 1993) is inimical to embryonic survival. The approach taken to regulate extracellular $\mathrm{pH}$ was to add the acid DMD to culture medium. This acid is not likely to be toxic in and of itself because it is nonmetabolizable and had no effect on the growth of hamster embryos when $\mathrm{pH}$ was adjusted to a value similar to control embryos (Carney and Bavister, 1987). Rather, it is the decrease in extracellular $\mathrm{pH}$ that appears important. The addition of DMD resulted in a slightly acidified medium that gradually increased in $\mathrm{pH}$ as the medium equilibrated with the carbon dioxide in the gaseous phase. The degree of acidification produced by DMD resulted in a medium $\mathrm{pH}$ similar to that of uterine secretions of cows fed a diet high in CP (Elrod et al., 1993; Elrod and Butler, 1993). This condition was catastrophic for embryonic growth. Indeed, no embryo exposed to 15 or $20 \mathrm{~m} M$ DMD developed to blastocyst. This sensitivity to DMD makes the bovine embryo similar to the mouse, where culture in DMD from zygote stage reduces development to the blastocyst stage (Edwards et al., 1998).

\section{CONCLUSIONS}

Present results are consistent with the idea that detrimental effects of feeding protein in excess of requirements on fertility in dairy cows are mediated in part through the direct effect of urea on the process of oocyte maturation and on diet-induced alterations in uterine $\mathrm{pH}$. The observation that effects of urea on oocyte maturation were exerted in a narrow range of urea concentrations leads to the speculation that the oocyte may undergo some concentration-dependent compensatory mechanism to overcome actions of urea and that effects of urea on oocyte maturation may not be important under situations that result in very high circulating concentrations of urea.

\section{ACKNOWLEDGMENTS}

The authors thank Rocío Rivera for assistance in with in vitro production of embryos; Khaled Mohammed and William Rembert for collecting ovaries; the employees of the Central Beef Packing Co. and Marshall Chernin (Center Hill, FL) for providing the ovaries; and Select Sires Inc. for donation of semen.

\section{REFERENCES}

Bavister, B. D., M. L. Leibfried, and G. Lieberman. 1983. Development of preimplantation embryos of the Golden hamster in a defined culture medium. Biol. Reprod. 28:235-247.

Butler W. R., J. J. Calaman, and S. W. Beam. 1996. Plasma and milk urea nitrogen in relation to pregnancy rate in lactating dairy cattle. J. Anim. Sci. 74:858-865.

Canfield, R. W., C. J. Sniffen, and W. R. Butler. 1990. Effects of excess degradable protein on postpartum reproduction and energy balance in dairy cattle. J. Dairy Sci. 73:2342-2349.

Carney, E. W., and B. D. Bavister. 1987. Regulation of hamster embryo development in vitro by carbon dioxide. Biol. Reprod. 36:1155-1163.

De Wit, A. A., M. L. Cesar, and T. A. Kruip. 2001. Effect of urea during in vitro maturation on nuclear maturation and embryo development of bovine cumulus-oocyte-complexes. J. Dairy Sci. $84: 1800-1804$.

Edwards, J. L., and P. J. Hansen. 1996. Elevated temperature increases heat shock protein 70 synthesis in bovine two-cell embryos and compromises function of maturing oocytes. Biol. Reprod. 55:340-346.

Edwards, L. J., D. A. Williams, and D. K. Gardner. 1998. Intracellular $\mathrm{pH}$ of the mouse preimplantation embryo: Amino acids act as buffers of intracellular pH. Hum. Reprod. 13:3441-3448.

Elrod, C. C., and W. R. Butler. 1993. Reduction of fertility and alteration of $\mathrm{pH}$ in heifers fed excess ruminally degradable protein. J. Anim Sci. 71:694-701.

Elrod, C. C., M. Van Amburgh, and W. R. Butler. 1993. Alterations of $\mathrm{pH}$ in response to increased dietary protein in cattle are unique to the uterus. J. Anim Sci. 71:702-706.

Hisanaga, H., H. Iioka, I. Moriyama, K. Nabuchi, K. Morimoto, and M. Ichijo. 1991. The mechanism of human placental urea transport: A study using placental brush border (microvillous) membrane vesicles. Asia Oceania J. Obstet. Gynaecol. 17:67-72.

Jordan, E. R., T. E. Chapman, P. E. Holtan, and L. V. Swanson. 1983. Relationships of dietary crude protein to composition of uterine secretions and blood in high-producing postpartum dairy cows. J. Dairy Sci. 66:1854-1862.

Kato, A., and J. M. Sands. 1998. Active sodium-urea counter-transport is inducible in the basolateral membrane of rat renal initial inner medullary collecting ducts. J. Clin. Invest. 102:1008-1015.

Larson, S. F., W. R. Butler, and W. B. Currie. 1996. Reduced fertility associated with low progesterone postbreeding and increased milk urea nitrogen in lactating cows. J. Dairy Sci. 80:1288-1295.

McEvoy, T. G., J. J. Robinson, R. P. Aitken, P. A. Findley, and I. S. Robertson. 1997. Dietary excesses of urea influence the viability 
and metabolism of preimplantation sheep embryos and may affect fetal growth among survivors. Anim. Reprod. Sci. 47:71-90.

Parrish, J. J., J. L. Susko-Parrish, M. L. Liebfried-Rutledge, E. S. Critser, W. H. Eyestone, and N. L. First. 1986. Bovine in vitro fertilization with frozen-thawed semen. Theriogenology 25:591-600.

Rajala-Schultz, P. J., W. J. A. Seville, G. S. Frazer, and T. E. Wittum. 2001. Association between milk urea nitrogen and fertility in Ohio dairy cows. J. Dairy Sci. 84:482-289.

Rivera, R. M., and P. J. Hansen. 2001. Development of cultured bovine embryos after exposure to increased temperatures in the physiological range. Reproduction 121:107-115.
Roseler, D. K., J. D. Ferguson, C. J. Sniffen, and J. Herrema. 1993. Dietary protein degradability effects on plasma and milk urea nitrogen and milk nonprotein nitrogen in Holstein cows. J. Dairy. Sci. 76:525-534.

SAS User's Guide, Version 5.4 Edition. 1989. SAS Inst., Inc., Cary, NC.

Sinclair, K. D., M. Kuran, F. E. Gebbie, R. Webb, and T. G. McEvoy. 2000. Nitrogen metabolism and fertility in cattle. II. Development of oocytes recovered from heifers offered diets differing in their rate of nitrogen release in the rumen. J. Anim. Sci. $78: 2670-2680$

Verkman, A. S., J. A. Dix, and J. L. Seifter. 1985. Water and urea transport in renal microvillus membrane vesicles. Am. J. Physiol. 248:F650-F655. 